\title{
How Did The Covid-19 Pandemic Effect Audience Attitudes in Webinars?
}

\author{
Yiloren Tanidir ${ }^{1}$, Fatih Gokalp ${ }^{2}$, Nebil Akdogan ${ }^{3}$, Ali Furkan Batur ${ }^{4}$, Çağrı Akın Şekerci ${ }^{1}$, \\ Sedat Egriboyun ${ }^{5}$, Mutlu Deger ${ }^{3}$, Bahadir Sahin ${ }^{6}$, ilker akarken ${ }^{7}$, Cemil Aydin ${ }^{8}$, Mesut \\ Altan $^{9}$, Oktay Ozman ${ }^{10}$, Murat Uçar ${ }^{11}$, Ahmet Gudeloglu ${ }^{10}$, Sakir Ongun ${ }^{12}$, Cem Akbal ${ }^{13}$, \\ and Ahmet Adil Esen ${ }^{14}$ \\ ${ }^{1}$ Marmara University School of Medicine \\ ${ }^{2}$ Hatay Mustafa Kemal University \\ ${ }^{3}$ Cukurova University Faculty of Medicine \\ ${ }^{4}$ Selcuk University \\ ${ }^{5}$ İzmir Ödemiş State Hospital \\ ${ }^{6}$ Marmara Universitesi Tip Fakultesi \\ ${ }^{7}$ Mugla Sitki Kocman University Faculty of Medicine \\ ${ }^{8}$ Faculty of Medicine, Hitit University \\ ${ }^{9}$ Hacettepe University \\ ${ }^{10}$ Affiliation not available \\ ${ }^{11}$ Faculty of Medicine, Alanya Alaaddin Keykubat University \\ ${ }^{12}$ Balikesir University \\ ${ }^{13}$ Acibadem University \\ ${ }^{14}$ Dokuz Eylül University
}

February 5, 2021

\begin{abstract}
Introduction: Following the Covid-19 pandemic, the face-to-face meetings are delayed to a future date, which is still not clear. However, seminars, meetings, and conferences are necessary for updating our knowledge and skills. The web-based seminars (webinars) are the solutions to this issue. This study aimed to show the participant behavior when webinars present at the Covid-19 pandemic era. Methods: Between December 2017 - July 2020, 58 webinars were broadcasted via the Uropedia, electronic library of SUST. Data of all webinars were collected with the YouTube analytics and application of the Uropedia. Data of streaming webinars included participant behaviors such as content views, engagement time, total unique attendees, average engagement time, and the number of audience to leads. Data were split into two groups; group-1 is webinars before Covid-19 (before March 2020), group-2 is the webinars during Covid-19. Results: Total broadcast time and total page view number were found to be 112.6 hours (6761 min.) and 15919, respectively. The median participant age was 40.1 years. Median content view and median engagement time were found to be $261.0 \mathrm{~min}$., and $12.2 \mathrm{~min}$., respectively. Comparison of two groups revealed a significant increment in the content views (group 1;134.0 range $=86.0-87.0$ and group 2; 414.0 range $=296.0-602.0$, $\mathrm{p}<0.001$ ) and the number of the unique attendees (group 1; 18.0 range $=10.0-26.0$ and group 2; 57.0 range $=27.0-100.0, \mathrm{p}<0.001$ ) following Covid-19. However, the median engagement time of the audience did not seem to change with the Covid-19 pandemic (group 1; 11.5 range=10.0-13.3 min. and group 2; 13.2 range=9.4-18.1 min., $\mathrm{p}=0.12$ ). Conclusion: The webinars are effective ways to share information and have many advantages, including low cost, reaching the high number of audiences. Audience number and page visits seemed to increase following the Covid-19 pandemic. However, The engagement time did not seem to
\end{abstract}


affect a critical attitude of the audience

\section{How Did The Covid-19 Pandemic Effect Audience Attitudes in Webinars?}

\section{Abstract:}

\section{Introduction:}

Following the Covid-19 pandemic, the face-to-face meetings are delayed to a future date, which is still not clear. However, seminars, meetings, and conferences are necessary for updating our knowledge and skills. The web-based seminars (webinars) are the solutions to this issue. This study aimed to show the participant behavior when webinars present at the Covid-19 pandemic era.

\section{Methods:}

Between December 2017 - July 2020, 58 webinars were broadcasted via the Uropedia, electronic library of SUST. Data of all webinars were collected with the YouTube analytics and application of the Uropedia. Data of streaming webinars included participant behaviors such as content views, engagement time, total unique attendees, average engagement time, and the number of audience to leads. Data were split into two groups; group-1 is webinars before Covid-19 (before March 2020), group-2 is the webinars during Covid-19.

\section{Results:}

Total broadcast time and total page view number were found to be 112.6 hours (6761 min.) and 15919, respectively. The median participant age was 40.1 years. Median content view and median engagement time were found to be $261.0 \mathrm{~min}$., and $12.2 \mathrm{~min}$., respectively. Comparison of two groups revealed a significant increment in the content views (group 1;134.0 range $=86.0-87.0$ and group 2; 414.0 range $=296.0-602.0, p<0.001$ ) and the number of the unique attendees (group 1; 18.0 range $=10.0-26.0$ and group $2 ; 57.0$ range $=27.0-100.0, p$ $<0.001)$ following Covid-19. However, the median engagement time of the audience did not seem to change with the Covid-19 pandemic (group 1; 11.5 range=10.0-13.3 min. and group 2; 13.2 range=9.4-18.1 min., $p$ $=0.12$ ).

\section{Conclusion:}

The webinars are effective ways to share information and have many advantages, including low cost, reaching the high number of audiences. Audience number and page visits seemed to increase following the Covid-19 pandemic. However, this era did not seem to affect a critical attitude of the audience, which is engagement time.

Keywords: Webinar, education, Covid-19, audience, behaviors

\section{What's already known about this topic?}

The education methods are evolving to digital over time. Webinars are also the most important part of education. Webinars play an important role for healthcare professionals to keep themselves up to date, especially after social isolation due to the pandemic. Studies have also shown that webinars satisfy the audience.

\section{What does this article add?}

Although the audience's satisfaction with the webinars is shown in the studies, their real behaviors are still uncertain in the literature, such as which topics they are more interested in, how long they watched, and after what time they are leave. In our study, we showed the change of audience behavior and interest in webinars during the pandemic era for the first time in the literature. We also made suggestions on planning future webinars.

\section{Introduction}


Coronavirus disease 2019 (Covid-19) infection is a life-threatening respiratory disease and first appeared in Wuhan, China, and spread worldwide in few moths and became a pandemic (1). All countries and communities are collaborating their effort to slow down the spread of infection. Undoubtedly, the pandemic's most negative impact has been and continues to be on the healthcare system and healthcare workers. All elective treatments were delayed, and the healthcare system began to struggle with the pandemic. As an effect of this, of course, all doctors started to spend their energies on this pandemic.

As another aspect of the work, all kinds of collective organizations are postponed as well as in the medical field. However, even if practical training is interrupted, theoretical training is important for physicians to update their knowledge and, more importantly, to keep their motivation high in this challenging pandemic conditions. The web-based seminars (webinars) are the solutions to this issue. The face-to-face online meetings are provided with advantages such as talking with mentors and taking answers to your questions on the area with the personal touch and social activities. The webinars have several advantages, such as no requiring travel, reducing cost, and watching at home comfort using different mobile devices. The technological advantages started to shifted education into digital fields.

Our association (Society of Urological Surgery) developed an application called Uropedia in 2017 (Figure 1). Uropedia is an online library for urologists compatible with the mobile ecosystem, including mobile phones, tablets, and Android TV. We share surgical techniques, videos of seminars, annual meetings, and a summary of changes on guidelines such as Covid-19 recommendations in this application. There is also a textbook prepared by our association, through which we can access theoretical information through this app.

During the pandemic, the webinars are increased all over the world. They are reduced costs and more comfortable, but the satisfaction of participants is still debatable. The literature recently focuses on webinars. Nevertheless, no published study has examined participatory behavior, and we even did not yet know the efficacy of webinars.

In this study, we aimed to evaluate audiences' behaviors before and after COVID-19.

\section{Materials and Methods}

\section{Application and Webinars}

Our official web site is 'www.uropedia.com.tr' . 'Uropedia' is a web-based application which is compatible with mobile devices, including mobile phone and tablets (Figure 1). Uropedia shows videos of seminars and surgical techniques, webcasts of annual meetings, a summary of guidelines, synopsis, or abstract of interesting studies that are updating very often. In addition, courses on statistics and article preparation are organized on this platform in order to contribute to the development of residents and young experts.. In order to keep this application up to date, a team of 15 people consisting of very dynamic and young urologists working with a 3 -person software team and 2 assistants was established. A constant effort is made to keep the site up-to-date and to include accurate information by distributing work within a certain hierarchy scheme. Application is free for all urologists during the pandemic era, and webinars were also free access Also, the webinars are announced and promoted using social platforms, (including Facebook, Twitter, Instagram ), and WhatsApp groups. We share a brief of topics, 'presenters' names, and free access links of webinars before and the same day. The participants could watch the seminars and comment or ask questions by using the application. The webinars were included spotlighted updates of guidelines, live or semi-live surgeries from mentors, current topics such as the Covid-19 pandemic. All webinars were published any day of the week at a consistent time (6.45 p.m. to 8.30 p.m. EST).

\section{Data collecting}

A total of 58 webinars were broadcasted between December 2017 - July 2020, via the Uropedia, the electronic library of SUST. Data of all webinars were collected with the YouTube analytics and application of the Uropedia. Data of streaming webinars included participant behaviors such as content views, engagement time, total unique attendees, average engagement time, and the number of audience to leads. Data were 
split into two groups and compared eachother; Group-1 is webinars before Covid-19 era (before March 2020), Group-2 is the webinars during Covid-19 pandemic.

\section{Statistical analysis}

Data was analyzed using the IBM Statistical Package for the Social Sciences version 22 (IBM SPSS Statistics for Windows, Chicago, IL, USA). Normality of distribution of the variables was checked using the ShapiroWilk test and Q-Q plots. The means were used when normality distribution. The median was used for variables that did not show normal distribution. The medians were compared using the Mann-Whitney U test. In the case of categorical data, the comparison was made using the chi-squared test. The $p$-value $<$ 0.05 was accepted as statistically significant.

\section{Results}

\section{Totally Data}

Total broadcast time was 112.6 hour $(6761 \mathrm{~min}$.) broadcast. The median age of participants was 40.1 years. Median content view and median engagement were 261.0 (range $=122.0-414.0)$ min. and 12.2 (range $=10.0$ 16.1) min. (summarized in Table 1). The median time of audience leads was 90.5 (range=82.0-106.0) min. A huge portion of participants was unsubscribed (average $87.5 \%$ ) because of sending free access links.

\section{After Pandemic Data}

When data split into two groups, the content views were significantly higher in group-2 than group-1 (134.0 range $=86.0-187.0$ and 414.0 range $=296.0-602.0$ in group- 1 and group-2, respectively, $p<0.001$ ) (see Figure $2)$. The median number of unique attendees was considerably higher in group $2(p<0.001)$. The engagement time duration was higher in group-2 (11.5 range=10.0-13.3 min. and 13.2 range $=9.4-18.1 \mathrm{~min}$. in group-1 and group-2, respectively), however, there was no significant difference between groups $(p=0.12)$. The time of leads was similar between groups (93 min. vs. $87.5 \mathrm{~min}$. in group 1 vs. group $2, p=0.23$ ). The peak engagement time was significantly earlier in group 2 (80.0 range $=60.0-100.0 \mathrm{~min}$. and 42.0 range:32.0-45.0 min. in group 1 and group 2, respectively, $p<0.001$ ) (see in Table 2).

\section{Discussion}

Since stepping into the digital world technological advances provide new education platforms, and webinars are starting to gain popularity for health professionals. While this process would take a decade if the Covid19 pandemic did not exist, the adaptation to digitalization took place very quickly within 1 year as the pandemic affected the whole world. Update and information sharing meetings, which are very important for all healthcare professionals, especially physicians, were naturally affected by this process. After physical seminars are stand overdue to the Covid-19 pandemic for social distancing, the webinars are essential for overcoming social distance for reaching information.

As far as we can reach and find, this study is the first in its kind in the literature, showing audience behaviors that will help planning future webinars. The webinars reached high view rates during the pandemic. The health information seminars were started to shift to online platforms, and the pandemic process is accelerated. The early studies of webinars focus, especially on health professionals' satisfaction and patients' education $(2,3)$. The authors concluded that all learners intended to reduce their own cancer risk. Patients felt more knowledgeable, prepared, and confident talking about cancer (2,3). For health professionals (HP), the studies generally use the surveys to investigate the results of webinars and showed that HP is satisfied and significantly improved their information, and they would deal with the webinar topics further (3-5). The education of the processes that can be defined as the education of tomorrow have now been laid. Our study demonstrated that the webinars are becoming the preferable site for reaching information. We explore that the mean watch time slightly increased when attractive topics or semi-live surgeries were broadcasted. However, it still does not exceed $20 \%$ of the whole broadcast period, which still seems too low.

The webinars are commonly promoting range 60 to $120 \mathrm{~min}$ (4). Our study supported that results, and when the webinars prolonged $90 \mathrm{~min}$, the participants were started to leave. Additionally, the webinars 
shorter than almost $80 \mathrm{~min}$., we did not investigate any significant fall pattern. Our study demonstrated that the time of leads was similar between groups and suggested that the webinars must be as concise and informative as much as it can be. We cannot interpret mean watch time, the number of the audience after breaks because of our webinars had no break.

The webinars reached top page views at the pandemic period after social distancing dismiss page views nearly decreased before pandemic levels. Furthermore, our suggestion is the webinar's watch time increasing day by day because of becoming reconciled to broadcasts. The time of reaching maximum participants has come earlier in the pandemic era; however, median watch time was similar between groups. To our guess, watching broadcasts at a comfortable place with other visual stimulus force participants to leave from webinars. In addition, it is necessary to take into account the broadcasting problems due to technical problems and the signal limitations in the country's infrastructure. Nevertheless, we have to say that webinar is more professional and technical problems have rarely been occurs lately.

Recently, the adverse emotional effects of the pandemic have been discussed. Especially the long working hours of healthcare professionals, social separation from friends, and constant infection also reduce employees' wellbeing (6). It has been shown to reduce their academic achievement. On the other hand, graduated healthcare professionals are willing to keep themselves updated due to changing treatment modalities and different approaches during the pandemic period. We also think that this increase in the audience depends on this in our study, but that webinars may not give the desired result because they cannot find what they want or are not satisfied with the presentations.

One of the significant limitations of this study is the lack of evaluated participants' satisfaction using surveys after webinars. Another limitation of the study is no enough demographic data of a considerable portion of participants because of using free access links.

\section{Conclusions}

The webinars effectively share information and have many advantages, including low cost, reaching many health professionals. The participations of webinars were higher in the pandemic era however, the median watch time of broadcast was not different and too low. The webinars must be concise and assessing an interesting topic.

\section{Author Disclosure Statement:}

There is no competing financial interests.

\section{Funding Information}

No funding was received for this article.

\section{Reference:}

1. Huang C, Wang Y, Li X, Ren L, Zhao J, Hu Y, et al. Clinical features of patients infected with 2019 novel coronavirus in Wuhan, China. Lancet [Internet]. 2020 Feb 15;395(10223):497-506. Available from: https://doi.org/10.1016/S0140-6736(20)30183-5

2. Cueva M, Thomas MK. Reflecting on the Importance of Webinars in Cancer Education. J cancer Educ Off J Am Assoc Cancer Educ. 2017 Jun;32(2):417-8.

3. Chiswell M, Smissen A, Ugalde A, Lawson D, Whiffen R, Brockington S, et al. Using Webinars for the Education of Health Professionals and People Affected by Cancer: Processes and Evaluation. J cancer Educ Off J Am Assoc Cancer Educ. 2018 Jun;33(3):583-91.

4. Ali SR, Dobbs TD, Whitaker IS. Webinars in plastic and reconstructive surgery training - a review of the current landscape during the COVID-19 pandemic. Vol. 73, Journal of plastic, reconstructive \& aesthetic surgery : JPRAS. 2020. p. 1357-404. 
5. Nadama HH, Tennyson M, Khajuria A. Evaluating the usefulness and utility of a webinar as a platform to educate students on a UK clinical academic programme. J R Coll Physicians Edinb. 2019;49(4):317-22.

6. Emotional Well-Being, Cognitive Load and Academic Attainment. MedEdPublish. 2020 Jan 1;9.

Table 1. Data of overall webinars

\begin{tabular}{lll}
\hline Variable & value & Min-Max \\
Mean age (years) & 40.1102 .0 & $77.0-119.0$ \\
$\begin{array}{l}\text { Duration of webinars (min.) } \\
\text { Number of unique attendees }\end{array}$ & 26.5 & $16.0-56.0$ \\
$\begin{array}{l}\text { Peak engagement time (min.) } \\
\text { Time of leads (min.) }\end{array}$ & 56.590 .5 & $40.0-86.082 .0-106.0$ \\
Engagement time (min.) & 12.2 & $10.0-16.1$ \\
Content views & 261.0 & $122-414$ \\
\hline
\end{tabular}

*All data was express as median;

Max. : Maximum, Min: Minimum, min. : Minute

Table 2. Comparison of two groups

\begin{tabular}{llll}
\hline Variable & $\begin{array}{l}\text { Groups } \\
\text { Before Covid Pandemic (Group 1) }\end{array}$ & $\begin{array}{l}\text { Groups } \\
\text { Before Covid Pandemic (Group 1) } \\
\text { Min-Max }\end{array}$ & $\begin{array}{c}\text { Group } \\
\text { While } \\
\text { Value }\end{array}$ \\
& Value & $79.0-131.0$ & 102.0 \\
Duration of webinars (min.) & 102.0 & $10.0-26.0$ & 57.0 \\
Number of unique attendees & 18.0 & $60.0-100$ & 42.0 \\
Peak engagement time (min.) & 80.0 & $88.0-105.0$ & 87.50 \\
Time of leads (min.) & 93.0 & $10.0-13.3$ & 13.20 \\
Engagement time (min.) & 11.4 & $86.0-187.0$ & 414.0 \\
Content views & 134.0 & & \\
\hline
\end{tabular}

*All data was expressed as median.

Max. : Maximum, Min: Minimum, min. : Minute

Figure 1: Uropedia application.

Figure 2. Change of content views during timeline 


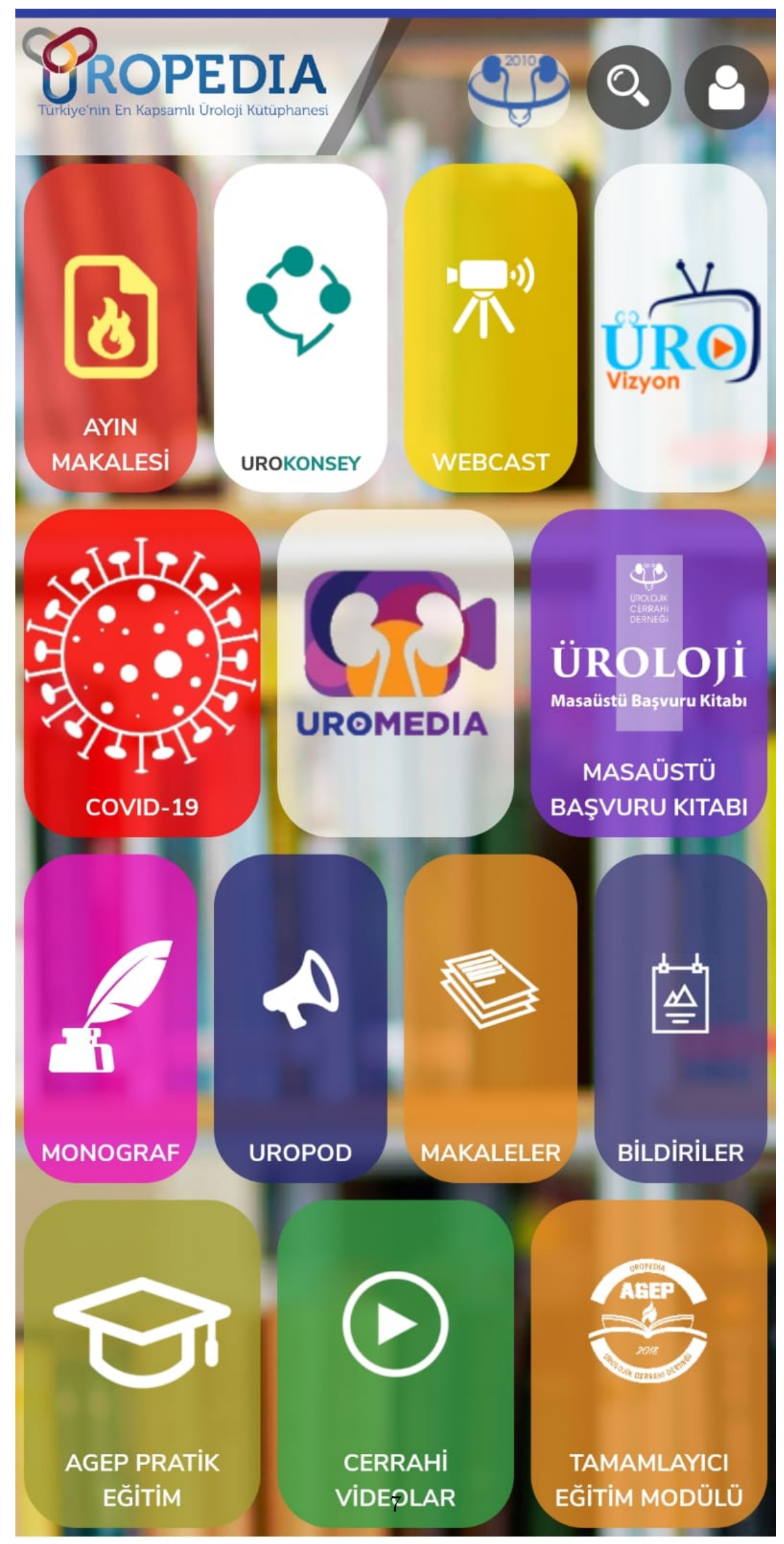




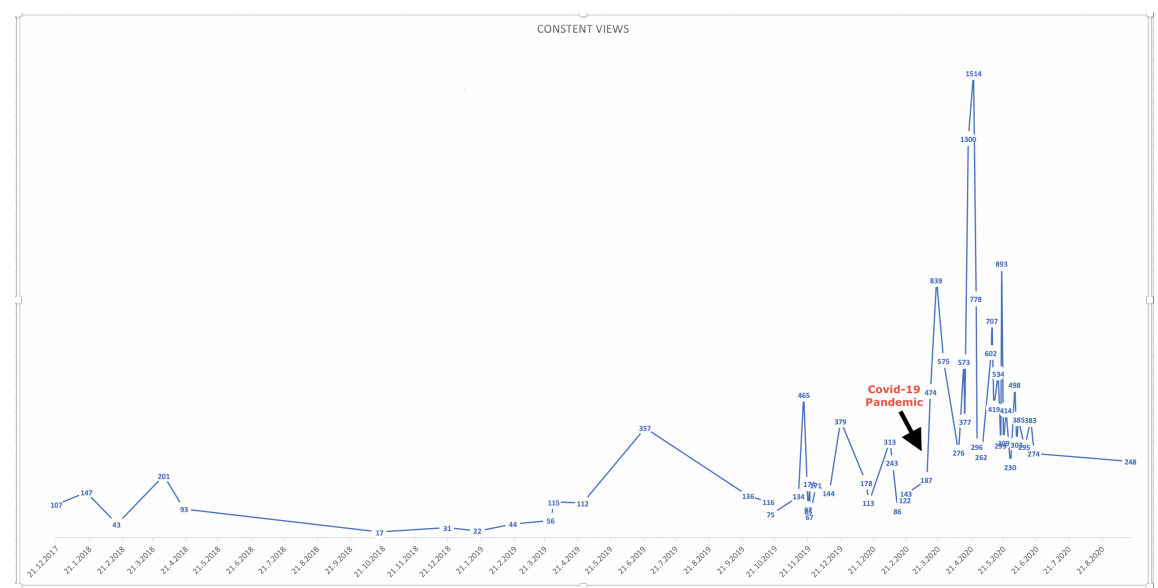

